\title{
Incidence of Pet Intoxications in the Emergency Clinic, Faculty of Veterinary Medicine Cluj-Napoca
}

\author{
Amalia-Marina NEAGU, Ecaterina DIAC, Andrei-Razvan CODEA, Andras NAGY, Adrian \\ OROS, Alexandra DREANC $\breve{A}^{*}$
}

Faculty of Veterinary Medicine, University of Agricultural Sciences and Veterinary Medicine, Cluj-Napoca.

* Corresponding author: Alexandra DREANCÄ e-mail: alexandra.dreanca@usamvcluj.ro

\author{
RESEARCH ARTICLE
}

\begin{abstract}
Veterinary toxicology is a common field in veterinary medicine, being a science closely related to other clinical and para clinical disciplines. The multitude of toxics and the ability of each organism to respond differently to them, nonspecific clinical signs and an inadequate anamnesis can often put the clinician in difficulty when seeking to diagnose. The aim of the study was to highlight the incidence of pet poisoning cases, over a period of 10 years of time at the emergency clinic, faculty of Veterinary Medicine Cluj-Napoca. An epidemiological study was performed with the help of the emergency clinic archive, where the files of the intoxicated patients were selected. The data were centralized in the Microsoft Office Excel. The results obtained revealed the sum of 256 cases of pet poisoning in the last ten years ( $0.611 \%$ of the number of cases registered during this period), of which the predominantly affected species was the dog of mixed breed. Also, within the most common poisonings, the ones with ethylene glycol and anticoagulants rodenticides were observed. In the present study a correlation was established between breed, age, sex and the most frequent incidence of poisoning, common toxins and the connection between the periods of the year.
\end{abstract}

Keywords: incidence; toxic; pets; poisoning.

Received: 28 September 2020

Accepted: 13 February 2021

Published: 14 May2021

DOI:

10.15835/buasvmcn-vm:2020.0036

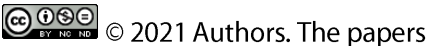
published in this journal are licensed under the Creative Commons AttributionNonCommercial-NoDerivatives 4.0 International

License

\section{INTRODUCTION}

Toxicology is a very broad topic in veterinary medicine due to the fact that animals are exposed daily to numerous toxins such as medicines for human use, household products, plants, chemicals, pesticides and poison from various species. In addition to the individual toxicity of different potential poisons, there is also a different mode of response of each organism (Gupta, 2012). In the science of toxicology, everything is based on the principle of dose and response. Toxicology means the knowledge of dangerous substances for patients including the dynamics of absorption, distribution, storage, metabolism, elimination, mechanism of action, therapy and antidote. Currently, synthetic toxins are the most important category of chemicals, these being the most common cause of poisoning in different species of animals. In recent years, a multitude of new chemicals and household products have appeared on the market, representing permanent and varied sources of toxic (Gupta, 2012).

Although animals are exposed to toxic agents on a daily basis, the incidence of intoxication in case studies is low compared to other pathologies (infectious, traumatic, neoplastic, etc.). Because the fundamental rule of toxicology is established by the father of toxicology, Paracelsus, namely "the dose makes the toxic", it is necessary to specify that each individual responds differently to the toxic (Gupta, 2012).

The aim of the paper is to sum up the number of cases of pet poisoning in the last ten years, to find the most affected species, the most representative toxins and the periods of the year in which they are more common. We will 
also try to distribute intoxications on certain breeds to determine if there is a link between the rate of intoxication and certain particularities of the breeds comparing the results obtained by us in the Faculty of Veterinary Medicine, ClujNapoca in the last 10 years with those of toxicology centers in Europe and in the USA. Thus, the importance of the paper is based on conducting an epidemiological investigation regarding the rate and the incidence of certain intoxications in the area represented, in order to establish a correlation between them.

\section{MATERIALS AND METHODS}

The study focused on the retrospective analysis of cases taken from the database of cases treated in the Emergency Clinic at the Faculty of Veterinary Medicine, Cluj-Napoca. Out of 41.854 files analyzed, 256 cases of intoxication were detected. Information related to species, age, sex, breed, toxic, period and years was noted. With the help of this information, we conducted a statistical study on intoxications in treated and expressed the percentage incidence of intoxications by graphical representations. The data were centralized in the Microsoft Office Excel program. Percentage correlations were made between the total number of toxicity cases and time periods, species and breeds.

\section{RESULTS AND DISCUSSIONS}

In the period 2009-2019 within the Faculty of Veterinary Medicine (FVM) were diagnosed 256 cases of poisoning in pets $(0.611 \%$ of the number of cases registered during this period) (Figure 1$)$. The number and the types of toxicants related to our FVM data are evidenced in Table 1. Moreover, data regarding the time of occurence is even more explained in Figures 2, 3 and 4 showing an increased number of cases, especially in the last three years, where an interpretation regarding the incidence of cases linked to the months of the year was made.

Table 1. Types of toxins found in cases between 2006, 2009-2019 within FVM Cluj-Napoca

\begin{tabular}{|l|c|c|c|c|c|c|c|c|c|c|}
\hline Toxins/Years & $\mathbf{2 0 0 6}$ & $\begin{array}{c}\mathbf{2 0 0 9}- \\
\mathbf{2 0 1 1}\end{array}$ & $\mathbf{2 0 1 2}$ & $\begin{array}{c}\mathbf{2 0 1 3}- \\
\mathbf{2 0 1 4}\end{array}$ & $\mathbf{2 0 1 5}$ & $\mathbf{2 0 1 6}$ & $\mathbf{2 0 1 7}$ & $\mathbf{2 0 1 8}$ & $\mathbf{2 0 1 9}$ & $\begin{array}{c}\text { Jan } \\
\mathbf{2 0 2 0}\end{array}$ \\
\hline Anticoagulants rodenticide & 3 & 4 & 0 & 10 & 3 & 14 & 32 & 21 & 27 & 3 \\
\hline Ethylene glycol & 5 & 3 & 1 & 1 & 3 & 2 & 3 & 14 & 3 & 2 \\
\hline Insecticide & 2 & 0 & 1 & 0 & 2 & 5 & 3 & 4 & 0 & 0 \\
\hline Household subst. & 0 & 0 & 0 & 0 & 0 & 0 & 7 & 9 & 4 & 0 \\
\hline $\begin{array}{l}\text { Veterinary and human } \\
\text { drugs }\end{array}$ & 0 & 0 & 1 & 0 & 0 & 0 & 2 & 1 & 4 & 1 \\
\hline Biotoxins & 0 & 0 & 0 & 0 & 0 & 0 & 3 & 3 & 14 & 0 \\
\hline Chocolate & 0 & 0 & 0 & 0 & 0 & 0 & 2 & 10 & 7 & 0 \\
\hline Plants & 0 & 0 & 0 & 1 & 0 & 0 & 1 & 0 & 1 & 1 \\
\hline Unknown & 1 & 1 & 0 & 1 & 2 & 1 & 0 & 5 & 2 & 0 \\
\hline
\end{tabular}

The increased number of cases could be explained by a higher number of patients who presented to the emergency department but also by the appearance of toxic agents that were not so representative often in the past. Thus, we can observe that chocolate intoxication has gone from not being taken into account between 2009-2016 to become in 2018 the $3 \mathrm{rd}$ most important toxic (Table 1, Figure 3).

The number of cases of poisoning with biotoxins, especially bee venom, has also increased, probably due to the increased interest that owners have in their animals. Thus, from no case reported until 2016, in 2019, 14 cases were reported (Table 1, Figure 4).

Household poisoning is also more common between 2016-2019, possibly due to the fact that the number of animals living with their owners is significantly higher, being more exposed to detergents, chlorine and other household products (Table 1).

In Europe there are several centers dedicated to poisoning or suspected poisoning, where there is also a laboratory for toxicological analysis. The center dedicated to animal poisoning located in Lyon, France provides permanent assistance to suspected cases of intoxication. In contrast to our findings, in France, in one year they receive around 1500-2000 samples for toxicological analysis and between 12.000 and 14.000 calls from owners who assume that their animals suffer from intoxication (Berny et al., 2009). 
Figure 1. The incidence of intoxications for a period of 10 years within the FVM Cluj-Napoca emergency hospital

\section{The ratio between the incidence of intoxications and the periods of the year}

Forrester and Stanley (2004) reported that animal poisoning normally occurs more during the summer, as found in reports by the ASPCA Animal Poison Control Center (USA). There is also an increase in December associated with the holiday season. The decrease in cases during the spring associated with their increase during the summer may be due to the fact that pets are safer in winter, staying longer in the house, with limited access to toxic agents. Anticoagulant rodenticides poisoning tends to be more common in the autumn-winter period due to the presence of toxic agents inside homes. Also, ethylene glycol poisoning is very high in winter when it is used as a frost prevention agent in car cooling systems. We must keep in mind that this substance is not used in areas with warm winters, the incidence of poisoning in those areas is low.

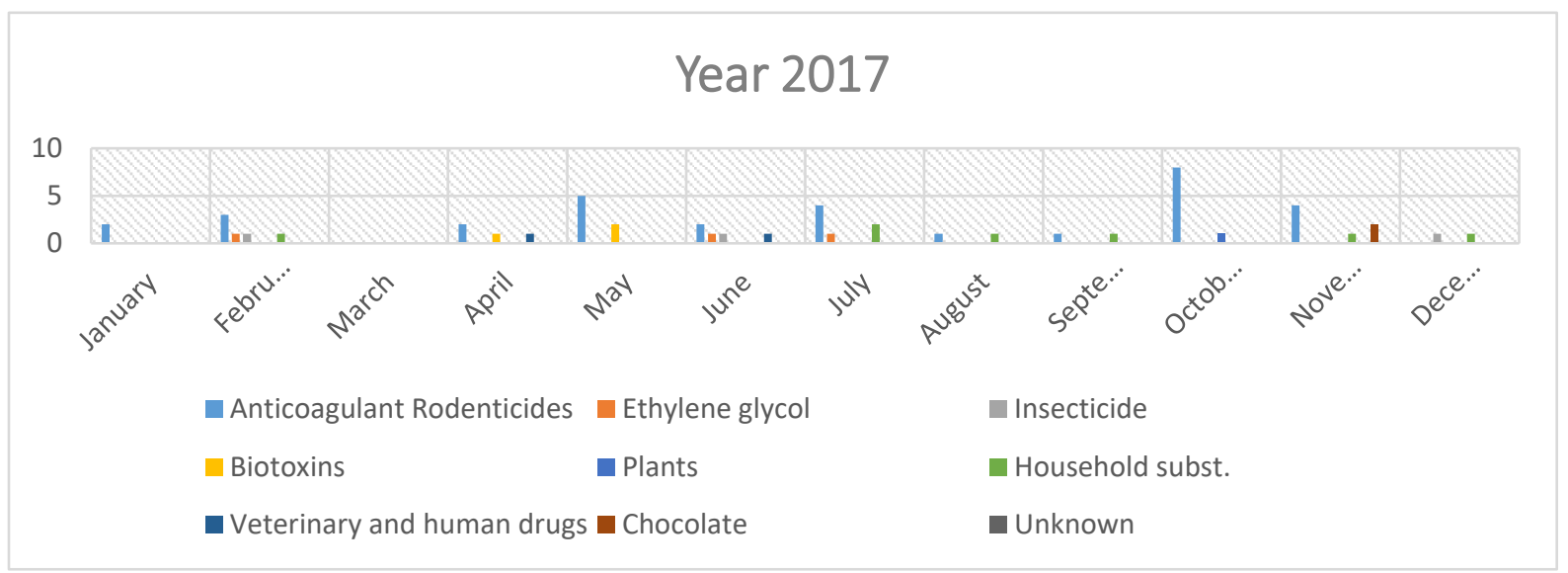

Figure 2. Incidence of intoxications for each month of the year in 2017 in the FVM Cluj-Napoca emergency clinic

Increased incidence of poisoning with lily, tulips or other ornamental plants in spring and increased chocolate poisoning around Christmas, Valentine s Day, Easter are also reported (Hautekeete, 2000; Volmer, 2001; Merola, 2002).

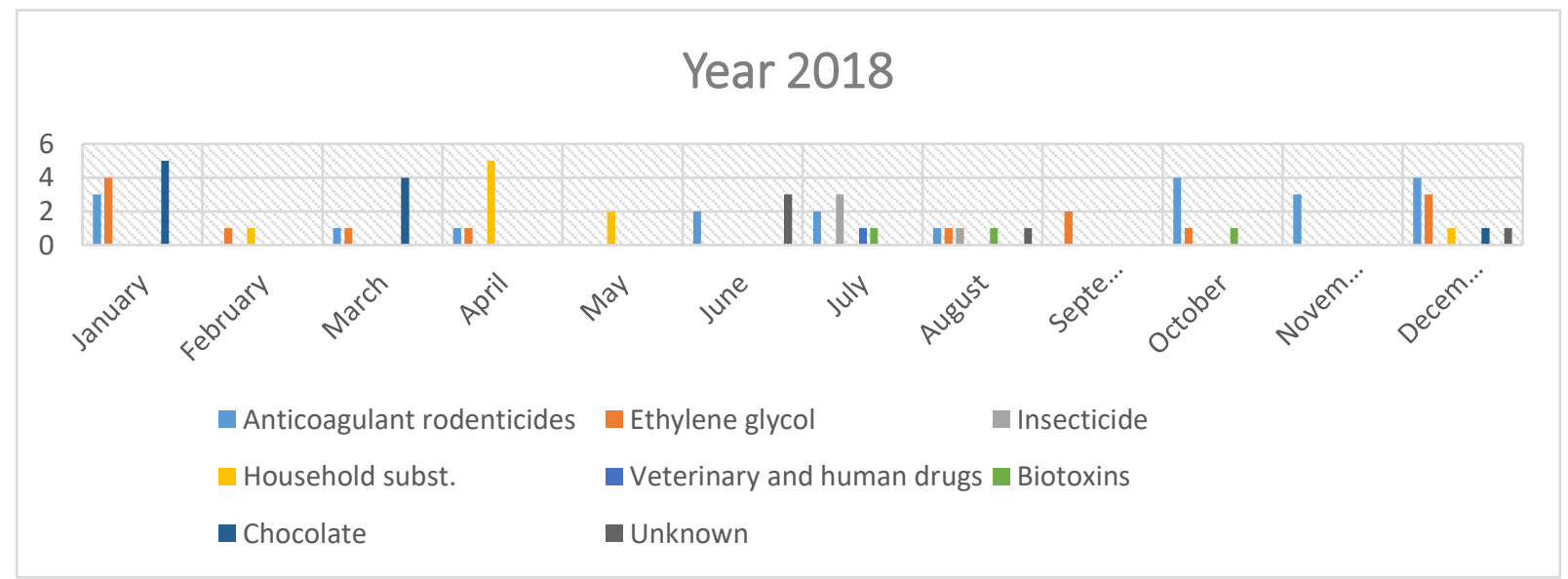

Figure 3. Incidence of intoxications reported every month of the year in 2018 within the FVM Cluj-Napoca emergency hospital 
In central Romania, Cluj-Napoca area, the increase in cases of anticoagulant rodenticides poisoning is more common in the cold period, autumn-winter, due to the increase in the number of rodents around the house and the placement of baits against them. It can be seen, however, that intoxications persist throughout the year, being a widespread diagnostic. There is also an additional explanation regarding anticoagulant rodenticide toxicity closely linked to either the ingestion of rodents that have in turn consumed anticoagulant rodenticides or intentional poisoning by less benevolent people. Chocolate poisoning is most common in December, around Christmas, the animals being prone to consumption due to the presence of chocolate in the house in larger quantities. There is also an increase in consumption in the spring months, which is associated with the feast of Easter.

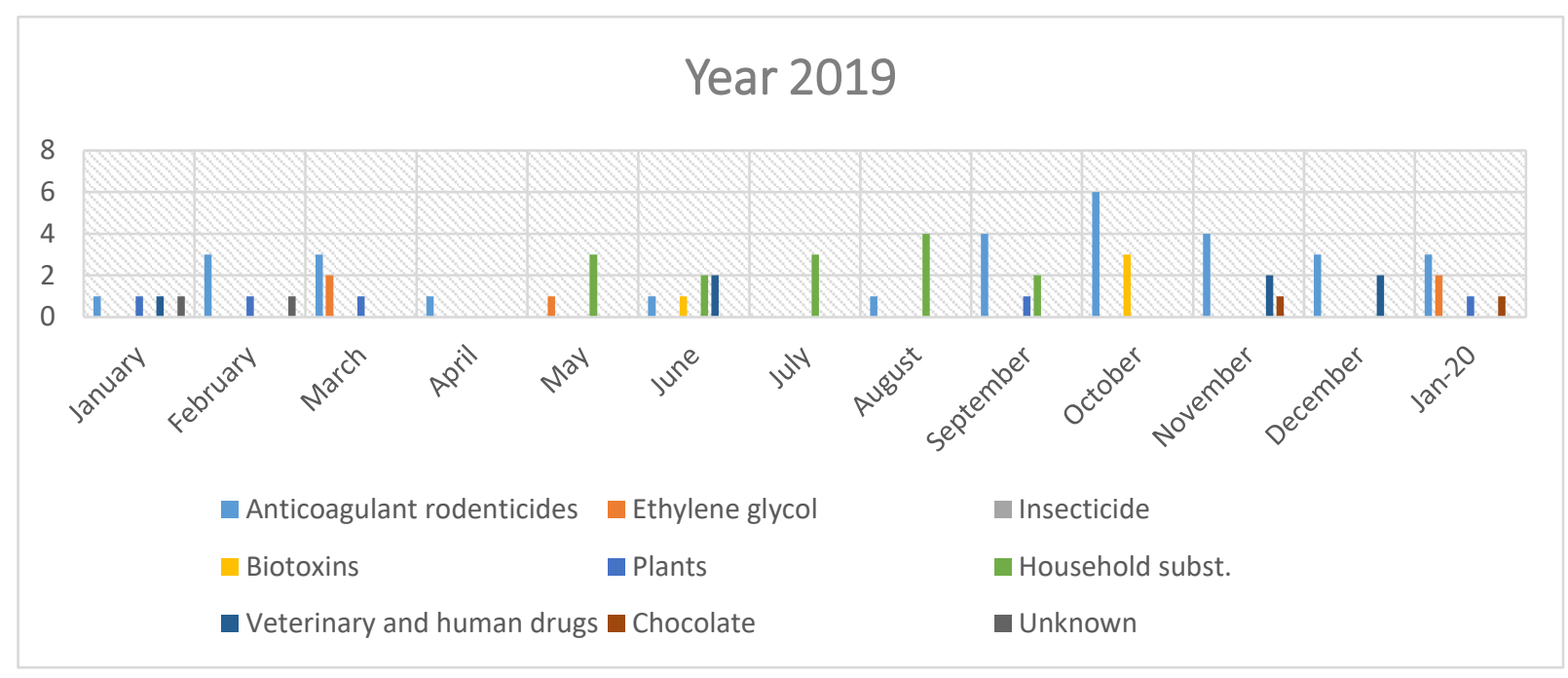

Figure 4 Incidence of intoxications reported every month of the year in 2019 and January of 2020 in the FVM Cluj-Napoca emergency clinic

The contact of pets with the venom of other animals, bees, wasps or venomous snakes is most common in the late spring-summer months due to the fact that the animals spend more time outside and they are prone to be in contact with the toxic in a higher ratio (Table 2). It is also observed that intoxication with household substances (detergents, chlorine, and disinfectants) is more common in spring and autumn probably due to the time of year dedicated to general cleaning. Insecticide poisoning seems to be more common in the summer and the others (drugs and plants) appear in a random way.

Table 2. The incidence of intoxications at different times of the year from FVM Cluj-Napoca

\begin{tabular}{|l|l|}
\hline Toxins & Period of the year \\
\hline Ethylene glycol & Spring-Autumn \\
\hline Anticoagulant rodenticides & Fall-Winter \\
\hline Chocolate & Winter (December) + March \\
\hline Venom (snake, bee) & June-August \\
\hline Household substances & Spring and Autumn \\
\hline
\end{tabular}

\section{The severity of clinical signs in poisoned patients}

Based on US statistics, the majority of poisonings (57\%) cause no clinical signs due either to exposure to small amounts of toxic or due to efficient and rapid decontamination of animals. Mild signs occur in $25 \%$ of exposed animals, moderate signs in $7-8 \%$ and major signs in $1 \%$ while lethality occurs in 2-3\% (Hornfeldt and Murphy, 1998). Mild signs are hypersalivation, mild vomiting, apathy, anorexia, etc. Moderate signs are more representative of a particular body system (vomiting, diarrhea, hypotension). The major signs are those that can be life-threatening or that can cause sequelae even if the animal is cured (seizures, kidney failure). In the US, the most commonly associated agents with mild or moderate signs are $19 \%$ pharmaceuticals, $14 \%$ pesticides, $10 \%$ plants, $8 \%$ cleaning products, $3 \%$ mushrooms. The agents associated with the major signs are pesticides $45 \%$, pharmaceuticals $25 \%$, plants $15 \%$, rodenticides $9 \%$, cleaning products $8 \%$. Patient death was most often associated with $24 \%$ pesticides, $17 \%$ pharmaceuticals, $16 \%$ anticoagulant rodenticides, $9 \%$ plants, $9 \%$ ethylene glycol, $8 \%$ cleaning products. Organophosphorus insecticides, ethylene glycol and anticoagulant rodenticides were the first agents on the list of agents responsible for the death of domestic animals (Hornfeldt and Murphy, 1998). 


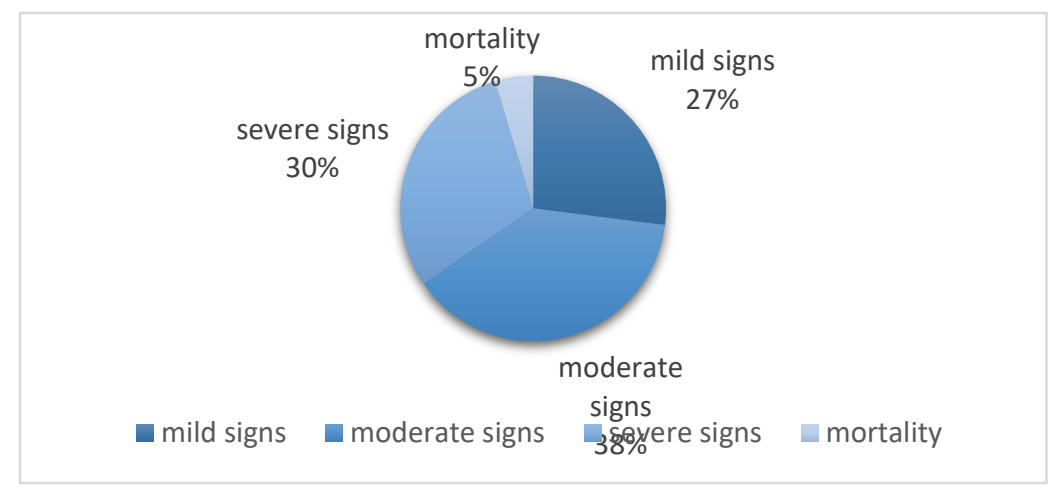

Figure 5. Incidence of clinical signs in intoxicated patients diagnosed between 2009-2019 in the FVM Cluj-Napoca emergency clinic

If we refer to the epidemiological analysis performed in the emergency clinic FVM Cluj-Napoca we can see that between 2009-2019 we have the ratio of different clinical signs manifested by animals as follows: most animals show moderate signs in relation to $38 \%$, severe signs occupy the second position by $30 \%$, mild signs are $27 \%$, and death is encountered in $5 \%$ of cases. The agents most frequently associated with mild or moderate signs are chocolate poisoning, insect bites, sometimes poisoning with more dangerous agents but in which rapid decontamination has been performed. Associations with severe signs are due to intoxication with anticoagulant rodenticides, ethylene glycol and unknown but very toxic agents (Figure 5).

Deaths are reported to be due to intoxication with anticoagulant rodenticides, ethylene glycol and pesticides, in which it was not possible to detect them in a timely manner or which ingested a very high dose of toxic and the wishes of euthanasia owners (Figure 5).

\section{Incidence of poisoning by species and breed}

If we rely on the data of an intoxication control center in the USA, we notice that the most frequent assistance for possible intoxications is requested in canines followed by felines in a ratio of 95-98\% (Hornfeldt and Murphy, 1998). Only $2-5 \%$ are cases of exotic animals. These reports have changed considerably since 1983 when cases of companion animal poisoning were $44 \%$ of total cases, whereas the remaining cases were found to be diagnosed in production animals (cattle, pigs, sheep) and equines (Trammel et al., 1985).

In many European countries such as Belgium, France, Italy, England, the most common species involved in a toxicological incident is the dog, followed by the cat (Gupta, 2012). Similarly, in the case of the epidemiological research conducted within the Faculty of Veterinary Medicine Cluj-Napoca, the data shows that out of 256 cases diagnosed as intoxication, 215 are attributed to dogs and 35 are attributed to cats. Thus, $86 \%$ of cases are represented by poisoning in dogs and 14\% in cats (Figure 6). The reasoning behind the higher number of cases in these species is due to the fact that, as companion animals, they have easier access to household toxicants. Poisoning cases in dogs appear in a higher ratio than in cats due to either the instinct of dogs to research the environment, or due to their much more developed curiosity. Thus, in the USA, the first position in the incidence of intoxications is also occupied by the canine species, representing 70-80\% of the cases (Hornfelds and Murphy, 1992). In 2005, such a comparative study of data from a U.S. poisoning center was conducted that evaluated more than 68,000 cases of dog poisoning and compared the data with American Kennel Club (2010) (AKC) dog breed registration statistics.

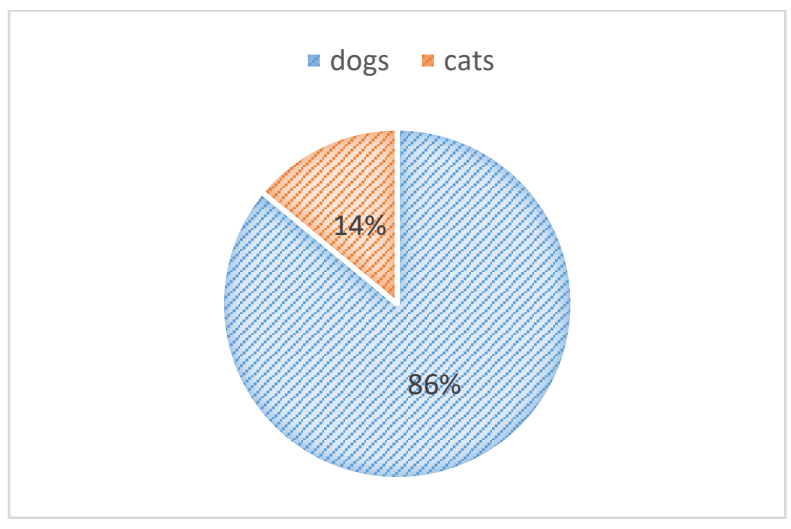

Figure 6. The ratio of the cases of intoxication between the canine species and the feline species during the ten years at the Faculty of Veterinary Medicine Cluj-Napoca 
The results show that the number of Labrador dogs registered in the AKC represents $15 \%$ of the total number of dogs registered in that year. In the same year, the cases of intoxication at Labradors were $17.5 \%$ according to the intoxication center. Thus, it is observed that the first position of intoxications is occupied by Labradors, which is due to the large number of existing dogs of this breed. It was observed, however, that there is not always a correlation between the frequency of intoxications and the number of dogs in this breed. For example, the Bichon Frize ranked 26th in the AKC and 15th in the incidence of intoxication (American Kennel Club, 2010).

Comparing the data obtained by us within the Faculty of Veterinary Medicine Cluj-Napoca we notice that most cases are found in the case of half-breed dogs ( 74 cases) due to the large number of mixed breed dogs in our area. The occupants of the second place are the dogs of the Bichon breed (16 cases), a breed that proved to be prone to intoxication and from the study conducted in the USA. In third place is the German Shepherd with 15 cases, probably due to the large number of dogs of this breed, followed in fourth place by Labrador with 13 cases. It can be seen that, according to research conducted in the US, the most prone to intoxication are Bichon, German Shepherd and Labrador (Table 3). We must also take into account the regional difference and the existence of higher frequency breeds in our country (Romanian Shepherd). Thus the incidence of poisoning in this breed will be higher than in other areas.

In the case of the epidemiological study carried out in FVM Cluj-Napoca, the most common are intoxications in halfbreed cats $96 \%$ (33 cases), followed by Siamese ( 1 case) and Persian ( 1 case) cats, due to the popularity of mixed-breed cats (Table 3).

Table 3. Incidence of breed poisoning in dogs between 2009-2019 at the Faculty of Veterinary Medicine Cluj-Napoca

\begin{tabular}{|c|c|}
\hline DOG BREEDS & NO. OF CASES \\
\hline MIXED BREED & 74 \\
\hline BICHON & 16 \\
\hline GERMAN SHEPARD & 15 \\
\hline LABRADOR & 13 \\
\hline DACHSHUND & 12 \\
\hline ROMANIAN SHEPARD & 12 \\
\hline FRENCH BULLDOG & 11 \\
\hline AMSTAFF & 6 \\
\hline ROTWEILER & 5 \\
\hline GOLDEN RET. & 5 \\
\hline BEAGLE & 5 \\
\hline YORKSHIRE & 5 \\
\hline PINSHER & 5 \\
\hline CAUCAZIAN SHEPARD & 4 \\
\hline COCKER & 3 \\
\hline COLLIE & 3 \\
\hline CANE CORSO & 3 \\
\hline HUSKY & 3 \\
\hline PEKINEZ & 3 \\
\hline POMERANIAN & 2 \\
\hline AKITA & 2 \\
\hline GERMAN SHORTHAIRED POINTER & 2 \\
\hline KANGAL SHEPHERD DOG & 1 \\
\hline SHITZU & 1 \\
\hline PUG & 1 \\
\hline POODLE & 1 \\
\hline BOXER & 1 \\
\hline VISZLA & 1 \\
\hline WEST HIGHLAND WHITE TERRIER & 1 \\
\hline CHOW-CHOW & 1 \\
\hline SCHNAUZER & 1 \\
\hline \multicolumn{2}{|l|}{ CATS BREEDS } \\
\hline MIXED BREED & 33 \\
\hline SIAMESE & 1 \\
\hline PERSIAN & 1 \\
\hline
\end{tabular}

According to literature, in America cases of intoxication in dogs did not indicate a certain gender predisposition, but it was indicated that the most prone to intoxication are dogs around 4 years old, also called young adults (Khan, 1999). In Europe, it has been indicated that the dogs most likely to be intoxicated are dogs around 2 years old (Berny et al., 2009). 
In contrast to the literature, no link between the age and sex of the animals (dogs) was established in the present study. Probably due to the habits of being more selective with what they consume, cats occupy about $11-20 \%$ of the animals reported in the study of intoxications in research conducted in the US. Thus cats become intoxicated 3 times less than dogs (Hornfeldt and Murphy, 1992). As in the case of dogs, there are no major differences between the gender and age of patients, not influencing however our findings. Cats may, due to their washing habits, be more susceptible to toxins that come in contact with the fur.

\section{Toxic agents involved}

In 2006, in the United States, the most common toxic agents were found to be the following: anticoagulant rodenticides, pharmaceuticals, and chocolate (Cope et al., 2006). Anticoagulant rodenticides and chocolate accounted for 50\% of all poisonings, followed by pharmaceuticals with $22 \%$. Exposure to pharmaceuticals has increased considerably since the first report in 1983 (Beasley, 1999), probably due to increased use of veterinary and human drugs. Comparing the data obtained in FVM Cluj-Napoca for the period 2009-2019 we can observe some similarities with those obtained in the USA, but also differences specific to the area.

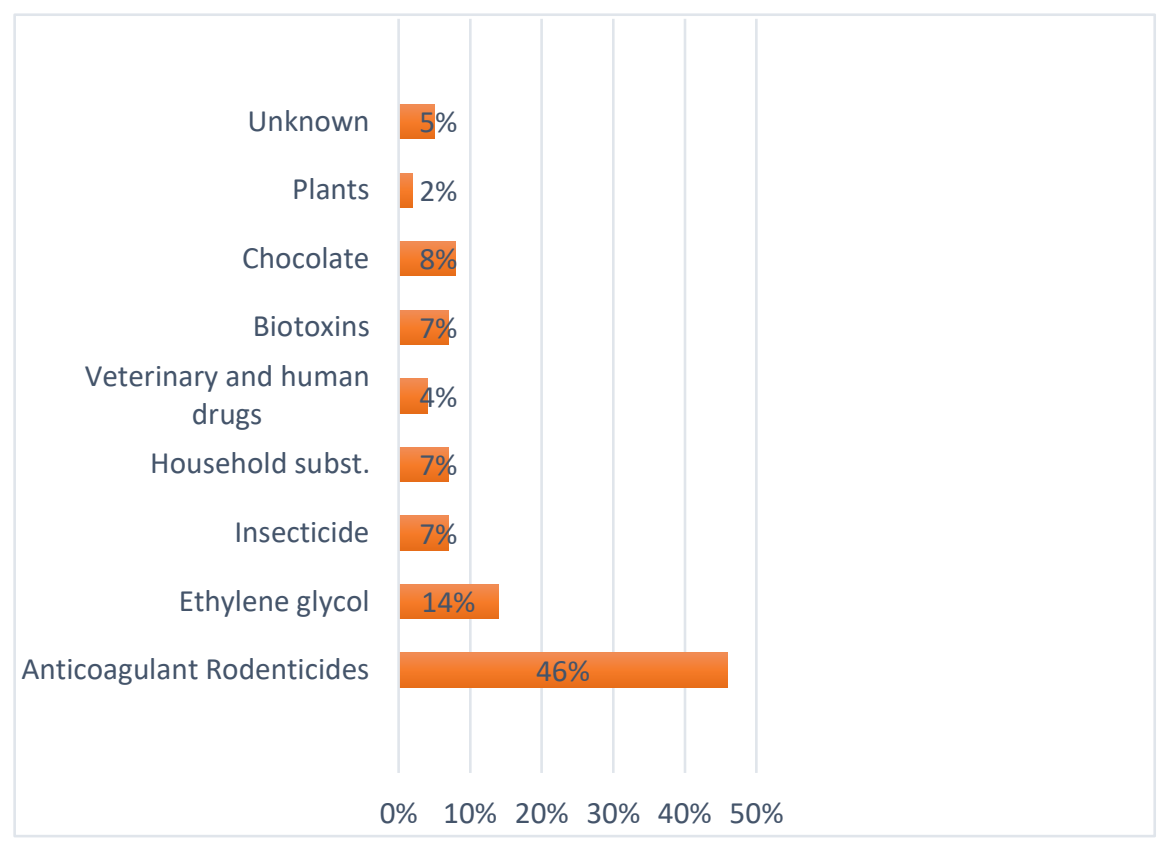

Figure 7. The ratio of the most encountered toxins between 2009-2019 within FVM Cluj-Napoca

In Romania, Cluj-Napoca, about $46 \%$ of all poisonings are anticoagulant rodenticides intoxications, $14 \%$ are given by ethylene glycol and $8 \%$ are poisonings with chocolate, $21 \%$ (7\% for each) bio toxins, household substances (detergents, acids, bases) and insecticides. A percentage of 5\% represents unknown substances treated as intoxications, $4 \%$ accounts for veterinary and human drugs toxicities, $2 \%$ are given by poisonous plants (Figure 7). The most constant intoxications in pets are given by the ingestion of anticoagulants and ethylene glycol which are constantly present from 2009 to 2019 , but there is still an increase in the number of cases by 2017. This is due to either a more drastic monitoring of cases, or a larger number of symptomatic animals at the emergency clinic.

\section{CONCLUSIONS}

In conclusion, in Romania, Cluj-Napoca area, the most frequent diagnosed intoxications are in the canine species, mixed breed, being given by anticoagulant rodenticides and ethylene glycol. Due to the lack of information campaigns, the persistence of these intoxications that appear annually can be observed. However, our study is the first to provide additional data to veterinarians in order to adapt to the growing needs and requirements to diagnose and treat such intoxications and also to owners to be aware of the risks of toxic substances from the outside environment or the interior of the houses. In addition, to our knowledge, there is no study to provide a correct epidemiological situation at a regional or national level. In Romania there is no reference toxicological center and a database to certify the incidence, frequency and occurrence of animal poisoning, which attests to the originality of the study. This work has highlighted that intoxications represent a veterinary medical emergency and such information could save the lives of companion animals.

\section{Acknowledgments}

This research did not receive any specific grant from funding agencies in the public, commercial, or not-for-profit sectors. 


\section{Conflicts of Interest}

The authors declare that they do not have any conflict of interest.

\section{REFERENCES}

1. American Kennel Club. Dog Registration Statistics 2004-2005. 2010; Available from: www.akc.org

2. Beasley VR. Toxicants associated with CNS stimulation or seizures. A Systems Affected Approach to Veterinary Toxicology Urbana: University of Illinois, College of Veterinary Medicine; 1999; p: 94-97.

3. Berny P, Caloni F, Croubels S et al. Animal poisoning in Europe Part 2: Companion animals. Vet; 2009; p:255-259.

4. Cope RB, White KS, More E et al. Exposure-to-treatment interval and clinical severity in canine poisoning: a retrospective analysis at a Portland Veterinary Emergency Center. J Vet Pharmacol Therap, 2006; p:233-236.

5. Forrester MB, Stanley SK. Patterns of animal poisonings reported to the Texas Poison Center Network: 1998-2002. Vet Hum Toxicol. 2004; p:96-99.

6. Gupta RC. Veterinary Toxicology, Basic and Clinical Principles, Second edition, Academic Press is an imprint of Elsevier 32 Jamestown Road, London, UK, 2012; p:340-359, 365-371, 2059-2071, 2101-2115, 2135-2146, 2156-2169, 2182-2200, 2226-2234, 2410-2426, 2470-2485, 2486-2493, 2495-2509, 2609-2620.

7. Hautekeete LA. Ice melts are health hazards. Vet Med, 2000; p:110-112.

8. Hornfeldt CS, Murphy MJ. Report of the American Association of Poison Control Centers: poisonings in animals. J Am Vet Med Assoc. 1992; p:1077- 1080.

9. Hornfeldt CS, Murphy MJ. American Association of Poison Control Centers report on poisonings of animals, 19931994. J Am Vet Med Assoc, 1998; p:358-361.

10. Merola VM. Anticoagulant rodenticides: deadly for pests, dangerous for pets. Vet Med. 2002; p:716-722.

11. Trammel HL, Buck WB, Beasley VR. National Animal Poison Control Center: seven years of service. 29th Annual Proceedings of the American Association of Veterinary Laboratory Diagnosticians, 1985; p: 183-191.

12. Volmer PA. How dangerous are winter and spring holiday plants to pets. Vet Med 2001; p: 879-884. 